\title{
Examining the management of stake and interest in a participatory design Facebook group
}

\begin{abstract}
This paper analyses the micro-dynamics of a participatory design (PD) Facebook group for breast screening. We argue that using online PD methods enables participants to be fully involved throughout the research process and can lead to meaningful outcomes and impact for the research. It is important to ensure that all stakeholders are equally involved in the research. As such, understanding how a user's stake or interest is managed can help to uncover how professionals and lay people participate together in such groups. A case study approach is adopted, with an example presented from a PD Facebook group established to develop a web resource around breast screening. 70 threads from the Facebook group were analysed in a naturalistic way using discursive psychology. The analysis shows how participants aimed to manage the dilemma of being seen as interested due to their professional identities through referring to joint membership of the design group. However, there were still challenges in ensuring that lay members' contributions were not diminished by more professional members. The analysis suggests that in an online PD group, moderators may be needed to ensure that potential conflicts of interest are managed appropriately and all members' views are heard.
\end{abstract}

Keywords: Participatory design; online research methods; discursive psychology; Facebook 
Participatory research is an umbrella term for any research which involves the local community or interested stakeholders in the design and planning of research (Cornwall \& Jewkes, 1995). Research frameworks which stem from this include participatory action research and participatory design (PD) (Kidd \& Kral, 2005). PD is a research framework which aims to involve different stakeholders in the design of a product (Clemensen, Rothman, Smith, Caffery \& Danbjorg, 2017). This paper is based on an online participatory design group which was established for the Word of Mouth Mammography ENetwork (WoMMeN) project, with the aim of improving information for women attending breast screening. The aim of this paper is to explore how analysing the data using a discursive approach can be beneficial to understanding the micro-dynamics of the group.

\section{Participatory design methods}

PD aims to involve participants throughout the research process, and aims to treat them as 'coresearchers', who bring their own valuable expertise to the research (Light \& Akama, 2012). There is an emphasis on ensuring that community knowledge and experience is heard, and that academic knowledge is not given primacy over this (Light, Egglestone, Wakeford \& Rogers, 2011). The sense is that participants should not just be seen as subjects, but instead should be understood as having relevant expertise and knowledge. For PD, trying to involve participants in a meaningful and instrumental way throughout the design process is of great importance (Light et al., 2011). In this sense, we can see how PD shares many of its features with participatory action research, which underpins some types of qualitative research, with both emphasising the participants having ownership of the research in some way (Gibson \& Riley, 2019; Light, Hansen, Halskov, Hill, Hackney \& Dalsgaard, 2013).

Although both qualitative and quantitative methods are used in PD research, there is often a strong qualitative component. For example, much PD research involves workshops with participants, the transcripts of which are then usually analysed thematically (e.g., Noergaard et al., 2017; Vosbergenet 
al., 2013). PD also uses methods such as fictional scenarios (Dindler \& Iverson, 2007) and group storytelling (Buskermolen \& Terken, 2012) to elicit qualitative data.

A key criteria of PD is 'collaborative development', in which researchers and designers codefine and co-develop the project together (Spinuzzi, 2005). Different participants must "continually reassess the activity under investigation and ...synchronize their interpretations.” (Spinuzzi, 2005, p.170). PD methods aim to promote collaboration between participants (Heinemann, Landgrebe \& Matthews, 2012), employing workshops, games and prototyping sessions (Spinuzzi, 2005). PD draws, then, on qualitative research methods, with both PD and qualitative research relying on interaction and negotiation between participants (Oak, 2011) or between the participant and the researcher. However, PD is distinctive in that it has a specific aim in terms of an outcome; that is, that a product will be designed at the end of it, and this will be of direct benefits to the user-group involved in the design (Light et al., 2011).

There are challenges in enabling truly equal involvement in the design process. Participants need to feel that they truly have ownership of the project itself (Light \& Akama, 2012). This means that participants need to feel that they have an equal say alongside the academics or facilitators of the project. Yet for academics, this can be a challenge as it is they who are responsible to the funding bodies, ethics committees, promotions panels and so on for making sure they get something publishable and useable from the research (Light et al, 2011). Therefore, ensuring that all stakeholders have an equal opportunity to contribute can be a challenge (Clemensen et al., 2007). Another challenge is how to ensure that stakeholders with expertise are not overly active within the group, leaving others unheard. Such issues are not unique to PD, and a recurrent feature of advice with regards to running focus groups is how to ensure that no one voice is too dominant (Braun \& Clarke, 2017). One particular issue with regards to this is that there has been a lack of engagement in the micro-dynamics of user design groups (Light \& Akama, 2012), although there are some exceptions. For example, conversation analytic research has shown that although PD aims to promote collaboration and consensus, there is an interactional dynamic at play (Heinemann et al., 2012) where participants will tend to work towards finding agreement, which aligns with an interactional 
preference for agreement, rather than making sure that everyone's voices and views are heard. These two challenges are related: a lack of understanding of the micro-dynamics has meant that there is limited understanding of how to ensure the user design groups create an environment in which participants are able to express their individual views. This paper aims to address this issue through examining the micro-dynamics of the interaction, specifically in relation to stakeholder interests.

\section{A participatory design Facebook group}

Being involved in a participatory design project involves a time commitment from participants and from the researchers (Clemesen et al., 2017). For design groups involving professionals, finding time for them to attend multiple workshops at a time that is also convenient for lay participants can be a particular challenge (Noergaard et al., 2017). If the project does not just involve a one-off engagement with the research (such as a focus group or interview), there can be additional challenges to retaining participant involvement, and this can add to the costs of the research. The WoMMeN project aimed to involve a variety of stakeholders to help with designing an online resource (or hub) to empower women in their decision making around breast screening. These stakeholders included mammographers, radiographers, radiography lecturers, women who had been diagnosed with breast cancer, and 'lay' women, who may or may not have previously had a mammogram. The challenges of getting all these women together for a number of workshops was considerable, and therefore it was decided to establish a closed Facebook group (see Galpin, Meredith, Ure \& Robinson, 2017).

The establishment of an online participant group for qualitative research purposes is not unheard of, particularly when conducting online focus groups (e.g., Ramo, Meacham, Thrul, Belohlavek, Sarkar, \& Humfleet, 2019; Boetang \& Nelson, 2016; Harmsen, Mollema, Ruiter, Paulussen, de Melker, \& Kok, 2013). A number of benefits are discussed of conducting online focus groups, including that users can post when they want (Braun \& Clarke, 2017), and that they have time to consider their responses (Williams et al., 2012). They also do not have to attend on any particular day, which can open up the participant pool immensely (Stewart \& Matthews, 2005). For the PD aspect of our 
research, similar benefits applied as well as additional others. As the project lasted a number of months engaging women consistently through the group allowed for regular participant feedback to be gained throughout the research process through questionnaires, interviews or specific researchfocused questions being asked (see Galpin et al., 2017). Users came to the group with an expectation of how Facebook groups worked. In this sense they had an understanding of the norms and expectations of posting in such groups (e.g., the asynchronicity of responses). . The group was, then, established by the researchers and as such would not pass what Potter (1996) described as 'the dead social scientist test'; that is, the interactions would not have existed if the researcher had not been there. As such, this data could be seen as somewhat 'contrived' and that the interactions which occur within the group are themselves not 'natural'. However, Speer (2002) notes that the distinction which is often made in conversation analysis and discursive research between naturally-occurring and contrived data is not necessarily a useful distinction as it privileges the method of data collection over the method of data analysis. Speer notes that data which has been collected in a 'contrived' fashion, such as using interviews or focus groups, can still be analysed in a 'naturalistic' way with an interest in how the interaction orients to that setting. This 'naturalistic' approach to analysis is taken here, in that although the data comes from a researcher-driven project, we are examining the interactions between participants in this group within this specific context. We therefore do not make any a priori assumptions about whether participants treated this group as, for example, a research group, a support forum or a simply an online community unless it is oriented to in the data.

Members of the group were recruited in January 2015, using a snowball sampling method, where women used their own social networks to recruit others to join the project. At its peak there were 111 women on the Facebook site, with a roughly equal split of practitioners and non-health professionals. The only exclusion criteria was that all members had to be women, as it was felt that including men would potentially inhibit women from engaging in conversations about the topic of breast screening. Upon joining the group, all women were directed by the leader of the research group to ethical materials including a participant information sheet and were asked to view these. It was made clear that if women chose to remain in the group and post in the group, that their posts may be used for 
research purposes. It is important to note that although the research team were involved in the group, there was no official moderator or facilitator and participants were free to start topics or respond to topics posted by others. The research team were not given instructions on when or how to post, although questions were posed by the research team when relevant.

As Light and Akama (2012) noted, little is understood about the microdynamics of PD groups, as the focus tends to be on more macro issues or on the outcome. We decided to take a discursive approach to the data (Edwards \& Potter, 1992), in order to allow us to evaluate the interactions between users, and how these might impact upon the usefulness of the eventual design outcome.

\section{Data and analysis}

All Facebook threads dated from February 2015 to July 2015 that related to breast cancer screening or the online resource were collected from the Facebook group. This resulted in a dataset of 70 threads. The data were then analysed using discursive psychology, following the stages of analysis outlined by Wiggins (2017). All three authors examined the 70 threads individually and discussed the various discursive actions which were prominent, including how participants provided advice and support, how they managed their stake and interest, and how they managed conflict. One particular issue that was noted as pervasive was how those with a particular professional identity, such as a health professional, manage their stake and interest in the group. Therefore, it was decided to focus on this specific analytical issue. All instances in which participants made their stake relevant in the interaction, both explicitly and implicitly were collected. We drew upon the conversation analytic process of 'next turn proof procedure': that is, that any turn in a conversation displays its understanding of the prior turn (Sacks, Schegloff \& Jefferson, 1974). We can, therefore, use the subsequent turns to ground our analysis of what the participant was doing in producing their turn (Sidnell, 2013). We examined, firstly, whether the posts in question received responses which oriented directly to an aspect of the original post. If responses were received, we analysed the 
recipient's response for "how s/he understood the prior turn, and we [used] this to ground our own analysis of what a speaker meant to be doing by producing that turn" (Sidnell, 2013, p. 79-80). When no response was received, then we drew upon a more ethnomethodologically informed approach to category use (Fitzgerald, 2012), to explore how categories were deployed in this particular context to be meaningful for participants. Extracts have been chosen for this paper in order to highlight a variety of practices used and to demonstrate the various ways in which these strategies were responded to. All names in the extracts have been changed for anonymization purposes.

\section{Stake and interest}

At its most basic level, stake and interest refers to the notion that anything a person says or does could be discounted or undermined as being a product of that individual's stake or interest in what they say (Potter, 1996). Potter notes that these terms 'stake' and 'interest' are "emblematic of a whole range of considerations that people may use to discount descriptions" (p.124). Orienting to someone's stake or interest suggests that they, or the institutions which they represent, have something to gain, or lose, from the description or argument they are making (Potter, 1996). For speakers this may lead to a potential dilemma of stake; that is, how to produce an account that attends to interests, without being undermined as being biased (Edwards \& Potter, 1992, p.158). For those individuals who have expertise in the topic being discussed, the potential dilemma of stake is that their views may be discounted as simply trying to impose their expertise (te Molder, 1999). From a discursive psychological perspective, stake and interest and dilemmas of stake are issues which are live for participants in the interaction. Therefore, to understand whether such issues are relevant in the interaction it is necessary to examine the interaction in detail to see if, and how, participants implicitly or explicitly orient to their own, or others', stake and interest and how those orientations are responded to. In PD groups, which also rely on a process of collaboration (Spinuzzi, 1995), it is particularly important to explore the interactional context in which various stakeholders' views are proffered and how these are then responded to. For our study we were interested in how participants 
with professional roles made their potential stake and interest relevant, and how this impacted upon users who did not belong to those categories.

Overall the analysis shows how users managed the potential for being seen as biased, but that in some cases professional identities and discourses could be used to potentially downplay the severity of women's complaints or issues. In the first section, we will demonstrate how and when participants invoked their own category membership, and the ways in which this could potentially hinder contributions from lay members of the group. In the second section, we will explore how participants oriented to the purpose of the design group in order to mitigate the potential for conflict between stakeholders and we will discuss the outcomes of such practices.

\section{Invoking category membership}

Participants often explicitly invoked their own membership of specific and relevant categories. The use of categories in this sense may warrant the speaker having certain sorts of knowledge that would be expected based on category membership (Potter, Edwards \& Wetherell 1993). In the following extract, Anna is responding to an introductory post by Meera, in which she has stated that due to her experiences, she would choose not to have a mammogram when the time comes.

\section{$\underline{\text { Extract } 1}$}

1 Anna Hi Meera, I'm a radiographer, mammographer, and lecturer in breast imaging. 2 Additionally I'm also a breast cancer survivor - only due to having regular

3 mammograms. The students (all grades from Assistant Practitioners throu to

4 Consultants) often discuss why women don't accept their invites - its such a big

$5 \quad$ complex topic and certainly uptake is recognised as being poorer within some ethnic

$6 \quad$ groups. I do hope this group, as well as your own reading and reflecting, WILL

$7 \quad$ change your mind and that through you the older women in your family and 
Anna explicitly introduces herself in terms of the categories into which she would place herself. These categories 'radiographer, 'mammographer' and 'lecturer in breast imaging' (line 1) confer category entitlement in terms of the types of knowledge which she has the rights to know and to talk about. Categories are 'inference-rich'; that is, categories "store a great deal of knowledge that members of a society have about the society" (Sacks, 1992, p.40-41). Therefore, by using these categories Anna not only claims rights to particular types of knowledge, but readers can also draw inferences about the potential meanings, interests, beliefs and views that she might have based on those categories. It is notable that Anna uses multiple categories here, where just one of these might have been sufficient (known as the economy rule; Stokoe, 2012). It is possible that as Anna belongs to multiple relevant categories, using them all in this introductory post allows for all her potential biases and interests to be clearly laid out to readers, who - because of the ongoing nature of the group - may be interacting with her multiple times. In other words, this may act as a 'stake confession' (Potter, 1996). There is, though, a dilemma of stake for Anna as it may be presumed that in her professional capacity she would have a particular interest in encouraging Meera to have a mammogram. The dilemma for Anna is how not to seem that she is "pushing" her view onto Meera as an expert.

It is worth noting that the categories which Anna names are delivered as a three-part list (Jefferson, 1990). Three-part lists have been shown to be rhetorically effective (Edwards \& Potter, 1992), in that they can demonstrate a sense of completeness or infer that the items named in the list are examples of a more general 'other'. However, this sense of completeness is then potentially countered by her use of a different, contrasting category 'breast cancer survivor' (line 2). Placing herself within the category of 'breast cancer survivor' can also manage her potential stake and interests. In other words, different entitlements and inferences can be drawn from this category compared to her other category entitlements. In doing so, she shows that although she has expertise which is important, it is this category-incumbency as 'breast cancer survivor' which is key. She grounds her advice in her experiences rather than just in her expertise and avoids telling Meera that her and her family members should have mammograms, but rather it is something that they should 
consider. She does this through placing the emphasis on Meera's 'own reading and reflecting' rather than on her own expert knowledge. However, when we examined the continuation of the thread, we noted that Meera does not at any point return to the thread or respond to Anna's post. We cannot make any claims about Meera's motivations for not posting, but there is the potential that this post from a professional has essentially shut down the discussion. In such cases, vital information about Meera's decision which could impact upon the design of the hub may have been lost.

In the following example, the potential level of expertise and knowledge is in a slightly different area. Catherine is responding to a discussion around what counts as a 'myth' when it comes to mammograms.

\section{$\underline{\text { Extract } 2}$}

$1 \quad$ Catherine Ah $h$, the nature of knowledge and the ontological paradigms in which we co-exist!! Of course no subjective opinions cans be 'wrong', by the very fact they

3 are subjective. What we have identified is a clash in the dual aims of the site in terms of the 4 people it will support.

This post is in response to a disagreement amongst other members of the user design group around 'myths', 'facts' and 'experience'. In line 1, Catherine uses the terms 'ontological paradigms'. The use of such a specialist term implicitly demonstrates Catherine's interest in the discussion as an academic, indicating her category entitlement to make claims about the 'nature of knowledge'. While Catherine makes relevant her academic identity, there is a dilemma in terms of her interests: she is an academic, but she is also part of the research team and so she could be seen as potentially biased if she makes pronouncements on the debate at hand. Catherine presents the issue as one which is understandably complex, rather than taking one side or another and as such she is 'being neutral' (Potter, 1996) pointing out that these are 'dual aims' (line 3), and so there is no hierarchy in terms of the aims. She also uses the vague term 'people' (line 4) rather than specifically talking about women going for 
breast screening, which avoids excluding mammographers or radiographers who are on the site. It is also worth noting that Catherine shifts the issue at the outset; the issue is not of two members of the site disagreeing, but rather it is that the research aims of the site are necessarily contradictory. However, despite the attempts at mitigating her potential stake and interest, the person to whom she was responding does not respond to her post. Although it is predominantly Catherine's academic identity which is made relevant through the discourse used, it is important to note that her other professional identities, including being a radiographer and the leader of the research team, may be omnirelevant across all of her interactions on the Facebook group as she welcomed all new members into the group as the leader of the research team (Fitzgerald, Housley \& Butler, 2009). In Extract 2, Catherine aims to mitigate this by invoking the purpose of the group, yet also demonstrates her identity through the use of academic discourse. While, as with the previous extract, we cannot make claims about why the recipient does not respond, it is important to consider the impact on the research if participants do not continue to contribute. However, we may also speculate whether self-excluding and non-participatory actions may offer a way for participants, as in these cases, to exercise power within a PD context (Kothari, 2001).

\section{Invocation of the design group as a means of managing stakeholder interests}

A particular discursive strategy which we found was that participants often drew on the user design group itself as a way of managing their potential stake in the interaction. They were able to orient to shared membership of the design group, as a way of potentially minimising their other professional identities which might be relevant. In this section, we analyse the different ways in which the design group is invoked in the interaction, and how this was responded to by recipients. In Extract 3, Jacqui is talking about a negative experience she had with a mammogram.

\section{Extract 3}

$1 \quad$ Jacqui I personally had an horrendous first experience at my mammogram which I

2 reported immediately to the unit manager, if I had put it on the web women would 

online..both my breasts were very roughly handled and I ended up having two four inch open bleeding wounds under each breast! Anna Thats horrendous Jacqui, so sorry to hear of this experience. Under breast soreness is a real issue that more women and mammographers need to be aware of, as without additional awareness and care, experiences like yours could happen. Were

9 you aware of having under breast skin issues prior to your mammogram? Did you

10 point this out to the mammographer?It certainly could be an interesting topic of

11 information and advice on the hub.

12 Catherine Hi Jacqui, that is truly a terrible experience. Can I ask whether this has

13 put you off attending next time? What would your message be for first time attenders?

14 Would you want to encourage them to attend in spite of your difficulties or would you

15 be suggesting they think twice? How can we learn from your experience in terms of

16 the messages we give new attenders?

Jacqui constructs her experience through a traditional troubles-telling structure (Jefferson, 1988), albeit within a single post. Jacqui starts the post with an announcement of the trouble (line 1), which also indicates her stance or attitude towards the experience. At the end of her post there is exposition on the precise nature of the trouble she is reporting 'roughly handled' and 'two four inch open bleeding wounds' (line 4-5). Jacqui also notes at the outset that she reported this issue to the unit manager (line 2). This section works to provide inoculation against the inference which could be made that Jacqui is simply whinging or complaining about this online. If Jacqui could be characterised as just a 'whinger' or 'moaner' (see Edwards, 2005), then potentially the facticity of her 
account could be undermined. Instead, by including that she had already reported this and it had been dealt with suggests that she is not simply repeating it to complain, but rather she is using this story to contribute to the ongoing discussion about whether experiences such as hers should be recounted on the web. In this way, Jacqui orients to the potential that she would be seen as having a specific grievance which would potentially bias her views towards posting negative experiences.

In the first response, Anna initially provides an affiliative assessment of the account, echoing Jacqui's words through using the same term 'horrendous' (line 6). The term affiliation can be used to describe actions which express support for the speaker's emotional stance (Lindstrom \& Sorjonen, 2013). Anna then moves her response away from Jacqui's own experience, making it a more general claim about how important this is in general for the categories of mammographers and women (lines 7-8). Anna then asks two questions focusing on Jacqui's behaviour; that is, whether she knew she had under-breast skin issues (line 9) and whether she told the mammographer about them (line 10). These questions move from treating the mammographer as responsible, as Jacqui did, to potentially holding Jacqui accountable for her own experiences, as she did not do something she should have done as a responsible client (telling the mammographer about under-breast soreness). Anna's final sentence 'it certainly could be an interesting topic of information and advice on the hub' (line 10-11) orients to their shared membership of the design group. It is used here as a resource for being able to discuss Jacqui's experience in order to help other women, rather than Anna being seen as challenging Jacqui's story, and as such may reduce the potential for Anna being seen as particularly biased.

Catherine's response also provides an affiliative assessment of Jacqui's experience, although in this case it could be seen as an upgraded form of affiliation from 'horrendous' to 'truly terrible' (line 12). Following her assessment, the rest of Catherine's post comprises four questions, which unlike Anna's post, do not engage in the details of Jacqui's experience, but instead makes her experience relevant to other women (e.g., 'what would your message be for first time attenders?'). Through attempting to draw out the implications of Jacqui's experience, she constructs Jacqui's post as being one which is relevant for the design of the hub, rather than as being a complaint about mammographers. In doing so, and through her use of the term 'we' (lines 15 and 16) she places herself an Jacqui within the 
category of 'design team members, and so potentially limits the possibility that she could be seen as imposing any form of expert knowledge or holding Jacqui accountable for her own behaviour. .

Both Catherine and Anna, therefore, use the design group as a resource for mitigating their professional identities. We can examine the subsequent response by Jacqui to explore how she treated these two responses to her original post.

\section{$\underline{\text { Extract 3a }}$}

1 Jacqui Anna I had no previous issues and didnt realise until I got home that was what

2 had been the result, and no Catherine it hasn't put me off as I'm now very aware! But

3 the managers made the mammographer aware so hopefully it wouldn't happen to

$4 \quad$ another woman! Women should know to make them aware if they have previous

$5 \quad$ issues with the skin under breast,I didnt but was purely a case of being very roughly

$6 \quad$ handled and the machine at the wrong height for me..

Jacqui responds to both Catherine and Anna in a single post. Her response to Anna challenges the underlying supposition that she may have been at fault and provides an account ('I had no previous issues'; line 1) for why she had not discussed this with the mammographer. Anna's recourse to the design group has not, then, been successful as Jacqui has responded to Anna's post as needing to provide an account for her actions. Jacqui then addresses Catherine's post (line 2), and does explicitly respond to the request to provide information which might be relevant for the design of the hub. However, Jacqui still provides an account of her actions and her motivations ('I didnt but was purely a case of being very roughly handled'; line 5), demonstrating an orientation to her own accountability made relevant in Catherine's post. It is worth noting that Jacqui only orients to the design group in her response to Catherine. This may suggest that she is orienting to Catherine's role as a researcher and therefore as someone who has a higher level of entitlement to ask design-related questions. Anna, 
despite having multiple roles (see Extract 1) has here made her professional identity as a mammographer relevant and as such Jacqui's response to her orients more to providing an account for why she is not at fault. In both responses, though, we can see that despite the orientation to the design group, the 'lay' member still presents a defence of her own behaviour. From this analytic lens, these extracts potentially show individuals with professional identities as downplaying a 'lay' member's experience.

We see something similar in the following post, which is also in response to the discussion about whether or not women should post negative experiences on the online resource in case it puts other women off going for a mammogram.

\section{Extract 4}

$1 \quad$ Jasmine I didnt have a good experience with my mammograms and that is a FACT

2 not MYTH so is the suggestion that no negative experiences are discussed? If so shall

$3 \quad$ I delete my post in case it scares people?

$4 \quad$ Marie Yes Jas, your experience is yours and is fact. Because you are a welcome part

5 of the design group you will read different parts of the project. One area we will

6 feature is the myths...ie some women think ur breast is squashed as flat as a pancake

7 or it is clamped between two steel plates...it may feel like that to some women..but

8 these things are myths. Some women have an experience like you did, some don't.

9 Your description helps us understand how best to respond...or wait for other women

10 to respond..as they did. Some agreed, some disagreed.

Jasmine constructs her experience as factual through the use of the phrase "that is a FACT not MYTH" (lines 1-2). The capitalisation, which can be used online to emphasise specific words, 
highlights that this is constructed as the reality of her mammogram. The reference to her own experience makes explicit her stake in the discussion. In other words, she demonstrates her stance towards posting such information.

Marie is a mammographer and a member of the research team, and so her response could potentially be seen as dismissing Jasmine's post, or as biased because she is a mammographer. Her post initially affiliates with Jasmine's ('yes Jas, your experience is yours and is fact'; line 4). Therefore, in supporting Jasmine's experience as valid, Marie affiliates with Jasmine's stance. Marie then makes the research focus of the group relevant ('because you are a welcome part of the design group'; lines 4-5), rather than her own category as a mammographer. In doing so, she highlights Jasmine's identity as part of the design group, rather than solely as a person who has had a negative experience of a mammogram. There are potentially different activities which are expected of "design group participant" - to read the information about the project, to discuss aspects of the project without bias, to consider how to manage information for all women. These are different category-bound activities to "client who had a negative experience" - who might be expected to share that experience, or to be critical of mammographers. Marie therefore reformulates Jasmine's negative experience as not being simply a negative experience, but her sharing it being a part of the role of the design group. Although this is an attempt to provide a shared category membership, it could also be viewed as potentially dismissing Jasmine's experience as valid, in that she is now placed into a different category from the one in which she had made relevant.

This post by Marie does not get any direct response from Jasmine, and the thread continues with a discussion of myths of breast screening. Later in the thread, Jasmine suggests that women may not report if they have suffered any discomfort during a mammogram, despite the fact that Marie has previously said that most women are 'not bothered' by the experience.

\section{Extract 5}

$1 \quad$ Jasmine Marie maybe some women do not feel they have a right to say anything

$2 \quad$ which could be just as easily confused as not being bothered? 

service would not have been introd uced. May I push a little bit as this is the design group...in a webspace what would you like to see on this topic...do you want pressure mentioned? Research data or other real womens experience?

Jasmine's post could be read as criticising mammographers (and potentially Marie in particular) for not realising that a woman has had a poor experience. In her reply, Marie does not affiliate with Jasmine's post, but rather immediately challenges it, providing an account 'I do read body language' (line 3), for how she knows that most women are 'not bothered'. . Marie makes her identity as a mammographer relevant by providing examples of how she ensures that women have had a positive experience (e.g., when they return 3 yrs later, I ask their experience'; line 3). She then opens this up more broadly to mammographers everywhere, by moving from an individualistic experience to the point that the service would not exist if it were such a negative experience for all women (line 4-5). Marie orients to the research purpose of the group at the end of the post, which again makes relevant their shared membership of the design group, rather than to their identities as 'client' and 'mammographer'. Jasmine's response to this engages with the questions that have been asked:

\section{Extract 5a}

$1 \quad$ Jasmine Marie I am interested in the nationals standard of force, weight,pressure. Where $2 \quad$ can I find out more about this and also maybe how the standards were set? Thanks

Jasmine directs her post to Marie and indicates her specific interests. However, it is notable that she does not refer to the design group or to content which should be posted on the hub, but rather she orients to what she is personally interested in 'I am interested in the nationals standard of force, weight, pressure'(line 1). In this way, she makes her own identity as a client relevant and implicitly 
resists her categorisation as a member of the design group. It is also notable that she adds a salutation 'thanks' (line 2) at the end of the post, which is somewhat unusual in the Facebook posts in this group. As such, this suggests a potentially increased level of formality to Jasmine's post, which might also highlight their difference in category membership. In this sequence of posts we can see that orienting to the design group does not alleviate the individual identities and category memberships of users. It also does not always mean that the hierarchies of power have been dissolved, and as such those with professional identities may inadvertently downplay the concerns of lay members.

\section{Discussion}

This paper has discussed the use of participatory design, and how professional and lay stakeholders may manage stake and interest. The WoMMeN research project reported here aimed to use an online design group to allow for more continued engagement with research. Having an online group, where everyone has equal rights to post may allow for participants to take more ownership of the project and its outcomes, which is an issue highlighted by Light and colleagues (2013). This paper has shown the benefits of taking a discursive approach to the analysis of such data. Through examining the data in a naturalistic way (Speer, 2002) we can understand the micro-dynamics of the group in detail. As noted, participants need to feel that they have an equal say in the project, and all stakeholders need to have an equal opportunity to contribute and that power is equally distributed (Clemensen et al., 2007). The analysis presented here shows that although participants clearly attempted to manage issues of stake and interest, particularly through drawing on the design group as a resource, the issues of power hierarchies between participants remain.

By invoking their category membership, participants present themselves as 'entitled' to have a certain view (Potter, 1996). The analysis has shown that participants in this situation work to mitigate the potential that they could be seen as 'pushing' their expert views onto others. In addition, they often orient towards joint category memberships, which implies that the structure of the group is more egalitarian than hierarchical, which is an aim of participatory methods (Light \& Akama, 2012). 
However, orienting to joint category membership of the design team did not necessarily mitigate the potential for health professionals to dominate the interaction or to potentially put off lay members from contributing more fully. For example, in Extract 2 we saw that the use of academic discourse potentially alienated other participants. PD literature suggests trying to ensure that the moderator uses participants' language (Skeels \& Pratt, 2008), and that the language used should be understood by all participants (Spinuzzi, 2005). Therefore, even though the online setting might be seen to be more egalitarian, it is still possible for expertise to dominate through pre-existing category entitlement and through the choice of language used.

The purpose of the design group itself was an important resource for participants in the group. Participants drew on the nature of the group when there was potential for conflict between stakeholder identities, such as in addressing negative experience of mammograms. However, we noted that across the data it was the health professionals or members of the research team, rather than lay members, who often made the design group relevant initially. This suggests that a hierarchical structure may have been implicit in the group, whereby those with relevant professional identities were focused on the research-orientation of the group, whereas lay members were more focused on their own experiences. When we examined the responses to invocation of the design group, we found that this did not always lead to an orientation to the design group from all members. There are cases in which both lay and professional members provided accounts and explanations for their behaviour in relation to that category membership. As such, orienting to shared identities did not mitigate the potential for professionals to potentially downplay or overrule lay participants' experiences.

A truly egalitarian participatory setting would allow participants to co-determine the boundaries of a group, the work that takes place within, and the roles that each participant plays. Drawing on Goffman's (1997) metaphors of performance, Kothari (2001) describes how practitioners may 'set the stage' of participatory groups so that participants are required to adopt particular roles that may actually be difficult for them to enact and at odds with the way they wish to present themselves. Our 
analysis reveals several instances in which participants are encouraged to re-cast their role to that of co-designers. Such requests were met with active resistance by Jasmine (Extract 5), and may also account for a withdrawal of participation in Extract 2. Here, we see how discursive analysis can not only reveal how stake and interest may be managed by those in positions of power, but also can reveal some of the power dynamics at play from different stakeholders through their decisions to orient to and / or engage with the stage set by the practitioners.

\section{Implications}

There is an increasing emphasis on ensuring an impact of research, and making sure that research benefits those being researched. Therefore, the use of PD in the field of psychology may help to ensure that participants are involved throughout the research, and that there is a tangible 'product' which is the outcome of that research, such as through designing online resources or apps (e.g., Mani, Kavanaugh, Hides \& Stoyanov, 2015; Donker, Petrie, Proudfoot, Clarke, Birch, \& Christensen, 2013; McKay, Cheng, Wright, Shill, Stephens, \& Uccellini, 2018). The PD process should benefit participants beyond a tangible product, too, whereby designers and researchers learn about users' values, whilst the users learn from designers about the possibilities and processes of design (Skeels \& Pratt, 2016). Although PD is not a purely qualitative method, it utilises qualitative methods such as group storytelling, (Buskermolen \& Terken, 2012) or the use of fictional scenarios and imagined futures (Dindler \& Iverson, 2007), which are effective in eliciting the implicit values participants attach to a particular context. .

The use of an online user design group may help to engage participants in a space where they feel comfortable, and are able to contribute in a consistent way. However, while all participants may have similar opportunities to participate, the fact that the PD group appears on social media does not mean that potential power hierarchies between different groups are ameliorated. The research team behaved as co-researchers on the Facebook group, not intervening from a position of power, but rather simply taking part in ongoing discussions. It appears, though, that moderators still need to intervene on occasion to ensure that the voices of lay members are heard. It is possible that as lay members' 
concerns were sometimes downplayed the final design of the hub may have been skewed towards professionals' concerns rather than lay individuals. It may therefore be prudent to consider whether lay members' should have additional opportunities to contribute outside of the design group setting. For instance, our design group data was complemented by an online survey that could be completed anonymously (see Galpin et al., 2017), usability tests and a focus group comprising lay members.

We would suggest that if establishing an online user design group, all members of the group should be clear on the design purpose and aims of the group, which can allow for a sense of ownership to develop (Spinuzzi, 2005). We would also argue that moderators play a role in ensuring that all members have similar opportunities to participate and that those with professional identities do not dominate the group. While it may be possible to draw on the purpose of the group to mitigate conflicts, users' identities and category memberships outside of being members of the design group should not be ignored when moderating or facilitating the group.

\section{Conclusion}

This paper has highlighted how engagement in a participatory design group may be encouraged by using an online group rather than face-to-face workshops or meetings. A potential concern with regards to using an online group is ensuring that all stakeholders have an equal voice, and that no one group is dominant. The analysis demonstrated that although professional members of the group attempted to mitigate their own stake and interest in the research, this still often had the impact of silencing or downplaying lay members' concerns. We have suggested that online user design groups should make use of a moderator or facilitator to ensure that all members are heard, so that the final design outcome reflects as the group needs as much as possible.

\section{References}


Arnhold, M., Quade, M., \& Kirch, W. (2014). Mobile applications for diabetics: a systematic review and expert-based usability evaluation considering the special requirements of diabetes patients age 50 years or older. Journal of medical Internet research, 16(4), e104.

Boateng, B., \& Nelson, M. K. (2016). Online Focus Groups with Parents And Adolescents with Heart Transplants: Challenges and Opportunities. Pediatric nursing, 42(3).

Braun, V., \& Clarke, V. (2013). Successful qualitative research: A practical guide for beginners. sage.

Buskermolen, D. O., \& Terken, J. (2012, August). Co-constructing stories: a participatory design technique to elicit in-depth user feedback and suggestions about design concepts. In Proceedings of the 12th Participatory Design Conference: Exploratory Papers, Workshop Descriptions, Industry Cases-Volume 2 (pp. 33-36). ACM.

Clemensen, J., Larsen, S. B., Kyng, M., \& Kirkevold, M. (2007). Participatory design in health sciences: Using cooperative experimental methods in developing health services and computer technology. Qualitative health research, 17(1), 122-130.

Clemensen, J., Rothmann, M. J., Smith, A. C., Caffery, L. J., \& Danbjorg, D. B. (2017). Participatory design methods in telemedicine research. Journal of telemedicine and telecare, 23(9), 780785.

Cornwall, A., \& Jewkes, R. (1995). What is participatory research?. Social science \& medicine, 41(12), 1667-1676.

Dindler, C., \& Iversen, O. S. (2007). Fictional Inquiry: Design collaboration in a shared narrative space. Co-Design, 3(4), 213-234.

Donker, T., Petrie, K., Proudfoot, J., Clarke, J., Birch, M. R., \& Christensen, H. (2013). Smartphones for smarter delivery of mental health programs: a systematic review. Journal of medical Internet research, 15(11), e247. 
Edwards, D., \& Potter, J. (1992). Discursive psychology (Vol. 8). Sage.

Edwards, D. (2005). Moaning, whinging and laughing: The subjective side of complaints. Discourse studies, 7(1), 5-29.

Fitzgerald, R. (2012). Membership categorization analysis: Wild and promiscuous or simply the joy of Sacks?. Discourse Studies, 14(3), 305-311.

Fitzgerald, R., Housley, W., \& Butler, C. W. (2009). Omnirelevance and interactional context. Australian Journal of Communication, 36(3), 45.

Foth, Marcus and Axup, Jeff (2006) Participatory Design and Action Research: Identical Twins or Synergetic Pair?. In Jacucci, Gianni and Kensing, Finn and Wagner, Ina and Blomberg, Jeanette, Eds. Proceedings Participatory Design Conference 2006: Expanding Boundaries in Design 2, pages pp. 93-96, Trento, Italy

Galpin, A.J., Meredith, J., Ure, C.M., \& Robinson, L. (2017). "Thanks for letting us all share your mammogram experience virtually": Developing a web-based hub for breast cancer screening. JMIR Cancer, 3(2), e17.

Goffman, E (1997) The Presentation of the Self in Everyday Life, in C. Lemert and A. Branaman (eds), The Goffman Reader, Blackwell, Oxford.

Harmsen, I. A., Mollema, L., Ruiter, R. A., Paulussen, T. G., de Melker, H. E., \& Kok, G. (2013). Why parents refuse childhood vaccination: a qualitative study using online focus groups. BMC public health, 13(1), 1183.

Heinemann, T., Landgrebe, J., \& Matthews, B. (2012). Collaborating to restrict: a conversation analytic perspective on collaboration in design. CoDesign, 8(4), 200-214.

Jayyusi, L. (1984). Categorization and the Moral Order (Routledge Revivals). Routledge.

Jefferson, G. (1990). List construction as a task and resource. Interaction competence, 63-92. 
Jefferson, G. (1988). On the sequential organization of troubles-talk in ordinary conversation. Social problems, 35(4), 418-441.

Judge, S., Floyd, K., \& Jeffs, T. (2015). Using mobile media devices and apps to promote young children's learning. In Young children and families in the information age (pp. 117-131). Springer, Dordrecht.

Kidd, S. A., \& Kral, M. J. (2005). Practicing participatory action research. Journal of counseling psychology, 52(2), 187.

Kothari, U (2001). Power, knowledge and social control in participatory development. In Cooke, B \& Kothari, U (Eds). Participation: The New Tyranny?, (pp.139-152). Zed Books, London.

Lindström, A., \& Sorjonen, M. L. (2012). Affiliation in conversation. In T. Stivers and J.Sidnell The handbook of conversation analysis, 250-369.

Mani, M., Kavanagh, D. J., Hides, L., \& Stoyanov, S. R. (2015). Review and evaluation of mindfulness-based iPhone apps. JMIR mHealth and uHealth, 3(3), e82.

McKay, F. H., Cheng, C., Wright, A., Shill, J., Stephens, H., \& Uccellini, M. (2018). Evaluating mobile phone applications for health behaviour change: a systematic review. Journal of telemedicine and telecare, 24(1), 22-30.

Molder, H. F. T. (1999). Discourse of dilemmas: An analysis of communication planners' accounts. British Journal of Social Psychology, 38(3), 245-263.

Noergaard, B., Sandvei, M., Rottmann, N., Johannessen, H., Wiil, U., Schmidt, T., \& Pedersen, S. S. (2017). Development of a web-based health care intervention for patients with heart disease: lessons learned from a participatory design study. JMIR research protocols, 6(5), e75.

Oak, A. (2011). What can talk tell us about design?: Analyzing conversation to understand practice. Design Studies, 32(3), 211-234. 
Owens, C., Sharkey, S., Smithson, J., Hewis, E., Emmens, T., Ford, T., \& Jones, R. (2015). Building an online community to promote communication and collaborative learning between health professionals and young people who self-harm: an exploratory study. Health Expectations, 18(1), 81-94.

Potter, J. (1996). Representing reality; Discourse, rhetoric and social construction. London: Sage.

Potter, J., Edwards, D., \& Wetherell, M. (1993). A model of discourse in action. American behavioral scientist, 36(3), 383-401.

Potter, J., \& Hepburn, A. (2005). Qualitative interviews in psychology: Problems and possibilities. Qualitative research in Psychology, 2(4), 281-307.

Ramo, D. E., Meacham, M., Thrul, J., Belohlavek, A., Sarkar, U., \& Humfleet, G. (2019). Exploring Identities and Preferences for Intervention Among LGBTQ+ Young Adult Smokers Through Online Focus Groups. Journal of Adolescent Health, 64(3), 390-397.

Roth, S. (1999). The state of design research. Design Issues, 15(2), 18-26.

Sacks, H. (1992). Lectures on conversation (Vols 1 and 2, edited by Gail Jefferson). Oxford: Blackwell.

Sacks, H., Schegloff, E. A., \& Jefferson, G. (1974). A simplest systematics for the organization of turn-taking in conversation. Language, 50(4), 696-735.

Sidnell, J. (2013). Basic conversation analytic methods. In J. Sidnell \& T. Stivers (eds) The handbook of conversation analysis, 77-99.

Speer, S. A. (2002). Natural' and contrived' data: a sustainable distinction?. Discourse Studies, 4(4), $511-525$.

Spinuzzi, C. (2005). The methodology of participatory design. Technical communication, 52(2), $163-$ 174. 
Stokoe, E. (2012). Moving forward with membership categorization analysis: Methods for systematic analysis. Discourse Studies, 14(3), 277-303.

Vosbergen, S., Janzen, J., Stappers, P. J., van Zwieten, M. C., Lacroix, J., Idema, K., ... \& Peek, N. (2013). A qualitative participatory study to identify experiences of coronary heart disease patients to support the development of online self-management services. International journal of medical informatics, 82(12), 1183-1194.

Wiggins, S. (2016). Discursive psychology: Theory, method and applications. London: Sage publications

Williams, S., Clausen, M. G., Robertson, A., Peacock, S., \& McPherson, K. (2012). Methodological reflections on the use of asynchronous online focus groups in health research. International Journal of Qualitative Methods, 11(4), 368-383. 